\title{
ANTI-CHANCROIDAL DRUGS TESTED BY THE HETERO-INOCULATION OF BUBO FLUID FROM THE TREATED DONOR
}

\author{
BY \\ R. R. WILLCOX \\ Physician in Charge, V.D. Clinic, King Edward VII Hospital, Windsor ; \\ Consultant Venereologist, St. Mary's Hospital, London
}

The effectiveness of different drugs in the experimental chancroidal infection in man may be tested by a number of means. One way is to reproduce the clinical condition by intradermal inoculation and to treat the developed lesion. This method has little advantage to offer over that of treating the clinical infection, for each volunteer is automatically a 'take'. More satisfactory methods are :

(a) By the auto-inoculation of bubo fluid intradermally into the forearm of the patient with the chancroidal bubo, treating simultaneously with appropriate drugs, and observing whether the experimental infection is aborted. This method also has disadvantages in so far as the controls all have to be other persons, which raises the objection of its not being a strict comparison.

(b) By the hetero-inoculation of volunteers and treating them with anti-chancroidal drugs. This method enables strict controls to be maintained.

(c) By first treating the person with the bubo with the drugs to be tested, and then, after treatment has been given, injecting the bubo fluid into others to ascertain whether or not it has lost its virulence.

All three methods were used by the author during 1949. Methods $(a)$ and $(b)$ are reported elsewhere (Willcox, 1950). The present paper describes method $(c)$.

\section{Technique}

In order to keep the local reactions to a minimum the inoculum must be small. $0.05 \mathrm{ml}$. bubo fluid obtained by aspiration is injected intradermally into the forearm. If both the donor of the fluid and the recipient are untreated, local tenderness will be apparent within 24 hours, and a definite tender papule will be established by 48 hours, and will become a small pustule within 48-72 hours after inoculation. If this pustule is needled, the presence of visible pus constitutes a 'take'. If the patient is then treated with effective drugs, such as penicillin in anti-syphilitic doses plus sulphonamides, the process stops here; otherwise it proceeds to the formation of a local chancroidal ulcer.
If the patient is treated by anti-chancroidal drugs at the time of inoculation no such reaction occurs apart perhaps from a non-tender papule at 24-48 hours. If the treatment which has been given is only partially adequate the papule may persist, and become tender, and the ulceration be delayed. Patients showing a papule that persists, therefore, require careful watching, and it is wise to treat such persons with drugs of proved effectiveness as soon as it is decided to conclude surveillance.

In the experiments of this series the virulence of the bubo fluid was first tested by inoculation into untreated volunteers. Treatment to the donor was then given, and 24 hours, and subsequently, after treatment had been begun, further specimens of bubo fluid were aspirated and injected into others in order to ascertain whether the fluid had lost its virulence. It was particularly striking that effective drugs caused the bubo fluid to lose virulence within only 24 hours after quite small doses had been given. The more purulent the fluid the greater the virulence; milky and semi-watery fluids generally possessed a lesser virulence, whatever treatment had been given.

\section{Experiments}

Twelve experiments were performed on 75 recipients of aspirated material from eleven treated donors. The donors themselves and twelve other untreated controls were also inoculated. Four of the experiments were in the nature of pilot studies, each involving only a single recipient without adequate control. In the remaining eight the virulence of the bubo fluid was definitely established by injections into others.

Material from three donors treated with sulphathiazole was injected into ten recipients, from one treated with aureomycin into thirteen recipients, from two with streptomycin into eleven recipients, from one with chloramphenicol into five recipients, from two with the 'single shot' treatment of procaine penicillin with aluminium monostearate into three recipients, from one with penicillin in oil-beeswax into twelve recipients, and from two 
with neo-arsphenamine into 21 recipients. Material from one of the latter donors, which had so obviously failed to become avirulent with neoarsphenamine, was later employed for the penicillin in oil-wax series.

Donors.-All had clinical soft sore which had been present in nine for an average of $10 \cdot 3$ days (extremes 5-21), with unilateral or bilateral chancroidal buboes. In ten of the eleven donors the blood Wassermann reaction was negative and in one it was positive. In eight the Dmelcos skin test for chancroid was positive and in three negative.

At the onset of the investigation it was attempted to control the diagnosis by the isolation of $H$. ducreyi. No culture service was available, although the organism is difficult to culture, and reliance had to be placed upon smears taken from the lesions. At an earlier phase in the same clinic some 570 smears taken on from one to three consecutive days from 243 male genital sores were examined for Ducrey's bacillus, and organisms morphologically resembling $H$. ducreyi were found in 257 instances from 144 patients. The specimens were taken, after cleansing with normal saline, from the undermined edge of the lesion. Positive results were often absent at first examination, and the not infrequent presence of a variety of other organisms made precise diagnosis difficult. However, the diagnoses of the patients showing positive results, based on repeated dark field and serological tests for syphilis, were : soft sore 75 , primary syphilis 65 , others 4.

Likewise similar organisms were detected in 29 of 142 smears taken from eighty females, the majority at routine examination. The common occurrence of such organisms in syphilitic sores, and sometimes, in females, in the absence of genital lesions, indicated that their presence was by no means necessarily confirmatory of an active chancroidal lesion.

Smears of bubo fluid from twelve patients with clinical chancroid, five of whom had shown the organism in the sore-smears at first examination, were next examined-with negative results in all. A number of smears taken from arm pustules were likewise examined, also with negative results.

Although it is likely that positive results would have been obtained, had the buboes been emptied of pus and the inside edges scraped after irrigation with saline, and a similar operation performed in the case of the arm 'takes', this procedure could not be adopted for obvious reasons. Therefore, although positive smears had been obtained from the sores of seven out of ten of the 35 donors employed in the entire investigation who were examined, it was decided to rely for the establishment of diagnosis upon clinical appearances backed by repeated dark-field and serological tests for the exclusion of syphilis, and the Dmelcos skin test for chancroid, rather than upon the use of smears.

Recipients.-These were all African Negroes with venereal diseases, usually syphilis often combined with soft sore. Soft sore was exceedingly prevalent in the area in question and an earlier skin-testing survey of patients in this clinic showed 129 positives ( 44.5 per cent.) out of 290 male persons tested. The results of the Dmelcos skin tests on the recipients, which showed a lower incidence of positivity than this previous series, appear in Table $\mathrm{I}$.

TABLE I

\begin{tabular}{ll|c|c|c|c}
\hline Results & $\begin{array}{c}\text { Posi- } \\
\text { tive }\end{array}$ & $\begin{array}{c}\text { Doubt- } \\
\text { ful }\end{array}$ & $\begin{array}{c}\text { Nega- } \\
\text { tive }\end{array}$ & $\begin{array}{c}\% \\
\text { Posi- } \\
\text { tive }\end{array}$ \\
\hline Takes . & $\ldots$ & 2 & 1 & 13 & $12 \cdot 5$ \\
No takes & $\cdots$ & 12 & 3 & 44 & $20 \cdot 3$ \\
\hline
\end{tabular}

There was a somewhat lower incidence of positive results in the 'takes' which might be construed as indicating that a Dmelcos positive person has some immunity against an experimental infection, but this was not borne out when the results of heteroinoculation were also considered. Of the 48 recipients whose Wassermann reactions are known positive results were recorded in 21 ( 43.8 per cent.).

\section{Results}

The results detailed below are tabulated in Table II.

Sulphonamide Drugs. - Three of the donors were given $1 \mathrm{~g}$. sulphathiazole four times daily. In the case of two donors bubo fluid was injected into themselves and into one other recipient, in each instance 24 hours after treatment had been begun, with the result that a 'take' occurred in none. Bubo fluid from the third donor was injected before treatment into two controls, one of whom showed a markedly pustular reaction at 72 hours with early ulceration. Neither this donor, who was then himself inoculated, or eight other persons injected at varying intervals after the onset of treatment, developed a 'take'. Thus one person was inoculated 24 hours after the donor had begun to be treated, four at 48 hours, and three at 72 hours-all without result. Sulphonamide drugs therefore proved particularly effective.

Streptomycin.-Pus from one donor was proved virulent by the production of a mild 'take' in one 
TABLE II

RESULTS

\begin{tabular}{|c|c|c|c|c|c|c|c|c|c|c|}
\hline & \multirow{3}{*}{ Drug } & & & \multirow{3}{*}{$\begin{array}{l}\text { No. of } \\
\text { Experiment }\end{array}$} & \multicolumn{2}{|c|}{ Controls } & \multicolumn{4}{|c|}{ Inoculation into } \\
\hline & & & & & \multirow{2}{*}{ Total } & \multirow{2}{*}{ Take } & \multirow{2}{*}{ Donors } & \multicolumn{3}{|c|}{ Other Recipients } \\
\hline & & & & & & & & Total & Take & No take \\
\hline \multicolumn{2}{|c|}{ Sulphathiazole } & .. & .. & $\begin{array}{l}1 \\
2 \\
3\end{array}$ & $\frac{\overline{2}}{2}$ & $\overline{-}$ & $\begin{array}{l}\text { no take } \\
\text { no take } \\
\text { no take }\end{array}$ & $\begin{array}{l}1 \\
1 \\
8\end{array}$ & $\begin{array}{l}0 \\
0 \\
0\end{array}$ & $\begin{array}{l}1 \\
1 \\
8\end{array}$ \\
\hline \multicolumn{2}{|c|}{ Streptomycin .. } & .. & .. & $\frac{1}{2}$ & $\begin{array}{l}1 \\
2\end{array}$ & $\begin{array}{l}1 \\
2\end{array}$ & $\begin{array}{l}\text { no take } \\
\text { no take }\end{array}$ & $\begin{array}{l}5 \\
6\end{array}$ & $\begin{array}{l}0 \\
0\end{array}$ & $\begin{array}{l}5 \\
6\end{array}$ \\
\hline \multicolumn{2}{|c|}{ Aureomycin } & . & .. & & 3 & 3 & take & 13 & 1 & 12 \\
\hline \multicolumn{2}{|c|}{ Chloramphenicol } & .. & .. & & 1 & 1 & doubtful & 5 & 0 & 5 \\
\hline \multicolumn{2}{|c|}{ Neo-arsphenamine } & .. & .. & $\frac{1}{2}$ & $\overline{3}$ & $\overline{3}$ & $\begin{array}{c}\text { no take } \\
\text { take }\end{array}$ & 20 & $\begin{array}{r}\mathbf{0} \\
15\end{array}$ & $\begin{array}{l}1 \\
5\end{array}$ \\
\hline \multirow[t]{2}{*}{ Penicillin } & РОВ & .. & .. & & 23 & $18^{*}$ & take & 12 & 0 & 12 \\
\hline & PAM & . & .. & $\begin{array}{l}1 \\
2\end{array}$ & \multicolumn{2}{|c|}{ _donor $_{-}$} & $\begin{array}{c}\text { take } \\
\text { no take }\end{array}$ & $\begin{array}{l}2 \\
1\end{array}$ & $\begin{array}{l}0 \\
0\end{array}$ & $\begin{array}{l}2 \\
1\end{array}$ \\
\hline
\end{tabular}

* Includes Neo-arsphenamine recipients and controls

control. The donor was then treated with $0.5 \mathrm{~g}$. streptomycin twice daily for three days. $\mathrm{He}$ himself was inoculated forthwith and five others in addition-two at 24 hours, two at 48 hours, and one at 72 hours after the beginning of treatment. A 'take' was produced in none. In a second experiment fluid from another donor was injected into two volunteer controls, producing a definite 'take' in each case. The donor was then given $2.0 \mathrm{~g}$. streptomycin on the first day followed by $0.5 \mathrm{~g}$. twice daily for three days. He himself was inoculated forthwith, two others with pus aspirated at 24 hours, two at 48 hours, and two at 72 hours, after treatment had commenced. There was a 'take' in none, although the donor himself had a persistent non-tender papule which was needled on the sixth day but was not found to contain pus. Thus streptomycin was found to be very effective.

Aureomycin.-The aureomycin-treated donor received $250 \mathrm{mg}$. orally three times a day for two days and thereafter $250 \mathrm{mg}$. twice daily for one day. Prior to treatment inoculation into the arms of three volunteer controls produced a 'take' in all three. The donor was inoculated with his own fluid forthwith. There was no reaction at 24 hours, but at 48 hours a definite bump appeared which persisted at 72 and at 96 hours, when it was needled and contained no pus. In spite of the aureomycin taken orally this bump slowly proceeded to ulceration on the seventh day, and must be regarded as a 'take' although it subsequently healed without additional treatment. Fluid from the bubo taken 24 hours after the treatment with aureomycin had commenced was injected into three others and produced a 'take' in one. Further specimens taken at 48 hours, however, failed to produce a 'take' in three others as did further specimens injected into three others at 72 hours, two others at 96 hours, and two others at 120 hours.

Thus aureomycin also has a definite beneficial action against chancroid in man although it is not as marked as that of streptomycin or the sulphonamides. It is interesting to observe in this respect that Wetherbee and others (1949) reported that aureomycin exerts only a transient inhibitory effect in vitro against $H$. ducreyi and that "streptomycin is probably the only (antibiotic) agent with therapeutic possibilities in this disease". As the above results indicate, the test tube is only the test tube. Zheutlin and Robinson (1950) now report the successful treatment of three clinical cases given 2 g. aureomycin daily for 7-14 days, and Greenblatt and others (1950) report yet another case.

Chloramphenicol.-Pus from one donor was injected into a single volunteer control and showed a 'take' at 48 hours. The donor was then treated with $0.25 \mathrm{~g}$. chloramphenicol given orally three times daily for three days. The donor was inoculated forthwith and a non-tender papule appeared at 24 hours; this was well-marked at 48 hours when it was needled but contained no pus. It persisted throughout the next five days when it 
was again needled and again contained no pus. It was then regarded as a 'no take', but 'insurance' treatment was given. Bubo fluid was aspirated at 24 hours and inoculated into three others with negative results and further specimens taken at 48 hours were injected into two others also with negative results. Thus chloramphenicol, like aureomycin, proved effective.

Neo-arsphenamine.-These experiments yielded striking results which were particularly interesting as they were the raison d'etre for the entire project. In the past, in many clinics in the tropics, soft sore has been, and often still is, treated with neoarsphenamine without any dark-field tests being performed to distinguish it from syphilis. It has been claimed by many medical officers that this treatment is effective in so far as the sores heal as they appear to do-ultimately. If this were indeed so, it could be argued that there could be no major objection in treating all penile sores by this method, granted that such treatment was also the 'official' treatment of syphilis. (Its value in syphilis is not for the moment under consideration.) Thus these experiments were undertaken in the first instance to compare the effectiveness of neo-arsphenamine with other more modern drugs in the treatment of chancroid. The results were most clear cut.

The first pilot experiment was uncontrolled. The donor received $0.45 \mathrm{~g}$. neo-arsphenamine intravenously and two days later bubo fluid was injected into him and into one volunteer without result. The second experiment, properly controlled, told a different story. The donor was given $0.45 \mathrm{~g}$. neo-arsphenamine followed on the second day by $0.15 \mathrm{~g}$., on the third and fourth days by $0.15 \mathrm{~g}$., and by a final dose of $0.3 \mathrm{~g}$. on the seventh day; he thus received a total of $1.2 \mathrm{~g}$. in one week. The donor himself was inoculated before treatment commenced as also were three controls, and all four showed definite 'takes'. Bubo fluid was subsequently taken from the donor at intervals and inoculated into others. Two were injected at 24 hours with one 'take', one at 48 hours with 'no take', five at 72 hours with five 'takes', four at 96 hours with two 'takes', four at 144 hours with four 'takes', and four at 168 hours with three 'takes'. Thus, in spite of vigorous treatment of the donor, the fluid showed no signs of losing its virulence. He was then given eight daily injections of 600,000 units penicillin in oil-beeswax and, although specimens of bubo fluid were subsequently taken at 48 and 72 hours after the first injection had been given, there were no 'takes' in twelve persons inoculated.
Thus neo-arsphenamine was proved to be inferior to sulphonamides, streptomycin, chloramphenicol, and penicillin in substantial doses.

Penicillin.-The donor treated with neo-arsphenamine, fluid from whom remained virulent throughout the week he was under treatment, and was shown capable of producing a 'take' in nineteen of 24 persons injected, has been described. The patient was then given eight daily injections of 600,000 units penicillin in oil-beeswax and material aspirated at 48 hours was injected into four persons, and at 72 hours into eight others. It was shown in this short time to have become completely avirulent.

Two small-scale investigations with donors given 'single shot' treatments with procaine penicillin with 2 per cent. aluminium monostearate were also performed. One donor had been given a single injection of 2.4 mega units of fortified procaine penicillin six days prior to aspiration and inoculation into himself and two others. There was no reaction in the two volunteers but the donor showed a pustule at 48 hours. Bubo fluid from another donor was inoculated into himself simultaneously with an injection of 2.4 mega units, and into a second person two days later, with a 'take' in neither.

It would appear, from these and other heteroinoculation experiments, that penicillin has some definite action against chancroid when given in a dose which produces and sustains an adequate blood level. If a high level is not sustained then the action of the drug is not adequate.

\section{Summary and Conclusions}

(1) The technique by which anti-chancroidal drugs may be tested by the intradermal inoculation of bubo fluid into volunteers after treatment has been given to the donor has been described.

(2) Twelve experiments were performed involving the injection of material from eleven treated donors into 75 recipients. The eleven donors and twelve other untreated controls were also inoculated. Four experiments, involving only four recipients, were uncontrolled in so far that it was not ascertained for certain that the bubo fluid was virulent betore treatment was given.

(3) The results clearly showed that sulphathiazole and streptomycin are effective both in preventing the experimental infection and in rendering the bubo fluid avirulent within 24 hours. Aureomycin was slightly less effective, and chloramphenicol also proved capable of aborting the infection.

(4) Penicillin in sustained dosage was also competent, but single massive doses of procaine 
penicillin with aluminium monostearate were less so. Neo-arsphenamine proved valueless.

(5) The above results have implications as regards prophylaxis. Aureomycin and chloramphenicol taken orally are known to influence syphilis, gonorrhoea, granuloma inguinale, and possibly also lymphogranuloma venereum, non-specific urethritis, and herpes simplex. As they will also prevent soft sore these "all purpose" oral antibiotics have great prophylactic possibilities.
I wish to express my thanks to Mr. E. A. Boulter for the performance of many of the pathological investigations.

\section{REFERENCES}

Greenblatt, R. B., Wammock, V. S., Chen, C. H., Dienst, R. B., and West, R. M. (1950). J. vener. Dis. Inform., 31, 45 .

Wetherbee, D. G., Henke, M. A., Anderson, R. I., Pulaski, E. J., and Kuhns, D. M. (1949). Amer. J. Syph., 33, 462.

Willcox, R. R. (1950). Ibid., 34, 378.

Zheutlin, H. E. C., and Robinson, R. C. V. (1950). Ibid., 34, 71 .

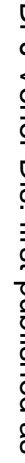

음 